\title{
Juvenile Parkinsonism: clinical and metabolic characteristics
}

\author{
BASTOS LIMA, GEORGINA NEVES, MANUEL NORA \\ From the Department of Neurology, Hospital Geral de Santo António, Oporto, Portugal
}

SUMmary Twenty one patients with idiopathic Parkinsonism beginning before the age of 40 years were investigated. The mean duration of the disease was 19 years. There was a good and sustained response to levodopa. Only four patients reached stages IV and V (Hoehn and Yahr). Intolerance to levodopa was observed in the more advanced stages of the disease. In the series the familial incidence of Parkinsonism ( 2 cases) and essential tremor ( 3 cases) was very low. Thyroid disorder, diabetes mellitus or macrocytic anaemia was not found in any of the cases.

Juvenile Parkinsonism has been recognised for many years. Willige, ${ }^{1}$ Mjones, ${ }^{2}$ Ota et $a l,{ }^{3}$ Martin, ${ }^{4}$ Carlier and Dubru, ${ }^{5}$ described several cases of juvenile Parkinsonism and did not find essential differences from classical Parkinson's disease apart from the frequent occurrence of familial cases ${ }^{1245}$ or consanguineous marriage of the parents. ${ }^{3}$

In 1981 Yokochi and Narabayashi ${ }^{6}$ defined juvenile Parkinsonism by its idiopathic character and its onset before the age of 40 years. They considered the clinical picture, evolution and pharmacological features of juvenile Parkinsonism different from classical Parkinson's disease. They subdivided their $\mathbf{4 0}$ cases, which represented $10.6 \%$ of their Parkinsonian population into three groups. The mean age of onset of the disease was rather younger in the third group (6-16 years), than in the other two (19-39 years in the first group and $16-38$ in the second group). In all groups rigidity and akinesia were the main symptoms, whilst tremor was less marked. Dystonia of the foot was the usual first symptom in the third group. Mental and autonomic disturbances were rare. The evolution of the disease was slower than in classical Parkinson's disease. Immediate and marked therapeutic response to levodopa was characteristic of the first and third groups. Severe dyskinesia, choreic or ballistic, occurred in nine out of 10 patients in the first group

Based on a poster presentation on the VIII International Symposium on Parkinson's disease, New York, 1985.

Address for reprint requests: Dr Bastos Lima, Department of Neurology, Hospital Geral de Santo António, 4000 Oporto, Portugal.

Received 28 February 1986 and in revised form 13 May 1986. Accepted 23 June 1986 and in three out of eight in the third. Therapeutic response to levodopa in the second group was more similar to classical Parkinson's disease than in the other groups. Familial incidence was found in 17 $(42.5 \%)$ of the 40 cases. The majority of the familial cases were siblings.

Barbeau and Pourcher ${ }^{7}$ investigated the clinical and metabolic characteristics of 32 personally seen cases of Parkinsonism which had begun before the age of 40 years, representing $9.4 \%$ of their Parkinsonian patients. They completed their study with information about another 135 patients obtained by mail in cooperation with the clinical attendant or the neurologist. They defined three subgroups of patients: (1) postencephalitic; (2) onset and course with predominant tremor; (3) onset and course with rigidity and akinesia. They found a high familial incidence of extrapyramidal symptoms $(46 \%)$, had a high prevalence of some metabolic changes: arterial hypertension, diabetes, familial early grey hair, macrocytic anaemia and thyroid disease. The analysis of the familial idiopathic cases led them to propose the existence of two genetic subgroups: $:^{7-9}$ (1) familial metabolic akinetorigid syndrome and (2) familial "essential tremorrelated" Parkinsonian syndrome associated with different kinds of extrapyramidal manifestations and different metabolic abnormalities.

We investigated our cases of juvenile Parkinsonism and conipared our results with previous reports.

\section{Material and methods}

We selected from a total of 228 patients with Parkinsonism, those whose disease had begun before the age of 40 years, excluding those of toxic, traumatic or tumour aetiology as well as those with multiple system degeneration. ${ }^{10-17}$ Our 
initial sample was 26 cases. Five of these had encephalitic ${ }^{18}$ (three cases) or post-encephalitic (two cases) Parkinsonism ${ }^{19} 20$ and were not included in this study. We then had 21 idiopathic cases. One of those had died; of the remaining 20, 19 were examined by at least two of the authors and were submitted to extensive clinical and laboratory testing. The following data were recorded: age of onset of the disease, present age (1984), sex, initial clinical symptoms, drinking and smoking habits, neurological examination with emphasis on the symptoms of Parkinson's disease and level of clinical disability (stages I-V) according to the Hoehn and Yahr Scale, ${ }^{21}$ assessment of depression according to a modified scale of Hamilton, general physical examination, slit-lamp examination, evolution, treatment and familial history of Parkinsonism, other neurological illness, arterial hypertension, diabetes and thyroidopathy. The laboratory investigations included blood tests (haemoglobin, haematocrit, RBC count and morphology, WBC and platelet counts, erythrocyte sedimentation rate, glucose, urea, uric acid, total protein, protein electrophoresis, SGOT, SGTP, calcium, phosphorus, alkaline phosphatase, copper and coeruloplasmin, thyroid function tests $\left(\mathrm{T}_{3}, \mathrm{~T}_{4}, \mathrm{TSH}\right)$ and VDRL. Seventeen patients had a CT scan of the brain.

\section{Results}

The 21 patients selected constituted $9 \cdot 2 \%$ of our total clinic of Parkinsonian patients. Twelve were female and nine were male. Disease onset was between the age of 12 and 39 (mean 30.8) years, and mean age in 1984 was 49.8 years. In 13 out of the 21 cases the disease began after the age of 30 years.

We subdivided the cases according to the onset and course of the disease into two groups: (1) with onset and course in which tremor was predominant; (2) onset and course with predominant rigidity and/or akinesia. The following information describes the groups (table).

Group 1 comprised 15 cases, five male and 10 female. The mean age of onset was 29.4 years, starting between the ages of 12 and 39. The mean age by 1984 was 51.3 and the mean duration of the disease was 21.9 years. Of these patients only two had reached stage IV (Hoehn and Yahr), both having an illness duration of 28 years. Another patient died from sepsis at the age of 50. Eleven of these were given levodopa for an average duration of 5.6 years with a good and sustained response, except in one patient who after 9 years of treatment and 28 years of the disease showed declining efficacy of levodopa and the "on-off" phenomenon. Another two patients in stages III and IV could not tolerate levodopa because it caused severe dyskinesia, but one of them benefited from bromocriptine treatment for 2 months. The other is being treated only with anticholinergic drugs.

Group 2 comprised six cases, four male and two female. The mean age of onset was 34.3 (range 27-39) years. The mean age by 1984 was 46.0 years and the mean duration of the illness was 11.7 years. Two patients reached stages $V$ and IV after 14 and 4 years of illness, respectively. All had levodopa treatment and benefited from it, but in the two more advanced cases, severe peak dose dyskinesia and "wearing-off" phenomenon were observed.

Mental deterioration was not apparent in any of the 21 patients. Marked depression was found in three patients and mild in four. We did not observe any autonomic disturbances. Four of our patients had arterial hypertension. Three were smokers and three were alcoholics.

We found a familial history of tremor in three of the patients from group 1 and none in group 2. The sister of one patient from group 1 had Parkinsonism with predominant tremor. The brother of another patient from group 2 had Parkinsonism with rigidity and aki nesia. We found a family history of arterial hypertension in five cases and of diabetes in three cases.

The laboratory results were normal or negative except for a high SGOT and SGPT in one of the alcoholic patients and a positive blood VDRL (negative in CSF) in another patient. CT scan of the brain was normal in eight cases. In the other nine, the results were as follows: general cerebral atrophy in two patients (one alcoholic); temporal cortical atrophy in four patients; temporal infarction in two patients (one associated with caudate nucleus infarction and one with cerebral atrophy); and calcification in the pallidum in one patient.

Table Juvenile Parkinsonism-clinical characteristics

\begin{tabular}{|c|c|c|c|c|c|c|c|c|c|c|c|c|c|c|}
\hline & \multirow{2}{*}{$\begin{array}{l}\text { Number } \\
\text { of patients }\end{array}$} & \multicolumn{2}{|c|}{ Sex } & \multirow{2}{*}{$\begin{array}{l}\text { Mean age } \\
\text { of onset } \\
(y r)\end{array}$} & \multirow{2}{*}{$\begin{array}{l}\text { Mean age } \\
\text { by } 1984\end{array}$} & \multirow{2}{*}{$\begin{array}{l}\text { Mean duration of } \\
\text { illness } \\
(y r)\end{array}$} & \multirow{2}{*}{$\begin{array}{l}\text { Mean duration of } \\
\text { levodopa (treat) } \\
(y r)\end{array}$} & \multicolumn{5}{|c|}{ Stages } & \multirow[b]{2}{*}{ Dead } & \multirow{2}{*}{$\begin{array}{l}\text { Family } \\
\text { history }\end{array}$} \\
\hline & & $M$ & $\bar{F}$ & & & & & $I$ & II & $I I I$ & $I V$ & $V$ & & \\
\hline \multirow{3}{*}{$\begin{array}{l}\text { Total } \\
\text { Onset with } \\
\text { tremor } \\
\begin{array}{c}\text { Onset with } \\
\text { rigidity/ } \\
\text { akinesia }\end{array}\end{array}$} & 21 & 9 & 12 & $30 \cdot 8$ & $49 \cdot 8$ & 19.0 & $5 \cdot 4$ & 0 & 10 & 6 & 3 & 1 & 1 & \\
\hline & 15 & 5 & 10 & $29 \cdot 4$ & $51 \cdot 3$ & 21.9 & $5 \cdot 6$ & 0 & 8 & 4 & 2 & 0 & 1 & $\begin{array}{c}\text { Essential } \\
\text { tremorg } \\
\text { Parkinson }\end{array}$ \\
\hline & 6 & 4 & 2 & $34 \cdot 3$ & $46 \cdot 0$ & $11 \cdot 7$ & $5 \cdot 0$ & 0 & 2 & 2 & 1 & 1 & 0 & Parkinsom \\
\hline
\end{tabular}




\section{Discussion}

The average age of onset of idiopathic Parkinson's disease is 55.3 years, starting between the age of 50 and 60 in two thirds of the cases. ${ }^{21}$ Onset of the disease before the age of 40 has been reported in between $9 \cdot 4 \%$ and $18 \cdot 4 \%^{67}$ of hospital based series, but is very rare in the general Parkinsonian population.

Parkinsonism beginning at such an early age raises diagnostic problems. None of our patients had a Kayser-Fleischer ring, hepatic disorder nor a low serum coeruloplasmin or copper, ${ }^{22}$ thus excluding Wilson's disease. ${ }^{2324}$ The juvenile form of Huntington's disease $\mathrm{e}^{25} 26$ was also ruled out by the absence of an antecedent familial history in all cases, dementia during the course of the disease and also the absence of caudate nucleus atrophy in the CT scan. The olivoponto-cerebellar atrophies ${ }^{1011}$ and striatonigral degeneration ${ }^{122728}$ can develop or begin with extrapyramidal symptoms of Parkinsonism. The long evolution of our cases, the absence of other neurological signs, their good response to levodopa and the CT scan findings, constitute grounds for considering any of these diagnostic possibilities unlikely. The differential diagnosis of juvenile Parkinsonism is further complicated by the neuropathological and biochemical analysis of some cases which have suggested the existence of several morphological ${ }^{29-31}$ and biochemical syndromes. ${ }^{432}$ In none of our patients were pathological studies carried out. Nevertheless in spite of the metabolic investigations the aetiology of Parkinson's disease in these subjects continues to be unknown and remains idiopathic.

The 21 patients of our series fulfil the criteria for a clinical diagnosis of idiopathic Parkinson's disease. ${ }^{21}$ In two patients the CT scan showed coexistent cerebral infarction. These patients are now in their 70s and have had a long evolution of Parkinsonism. Cerebral infarction was clinically detected in one of these patients, and by CT scan in the other who had severe arterial hypertension. A third patient had bilateral calcification of the pallidum. Basal ganglia calcification, especially involving the pallidum ${ }^{33} 34$ has been observed in patients with diverse symptomatology not attributable to the calcification and is not regarded as a nosological entity. Although Parkinsonism associated with basal ganglia calcification has been said to be resistant to levodopa treatment, ${ }^{35}$ our patient (who had normal calcium metabolism) responded well to the drug. ${ }^{36}{ }^{37}$ For these reasons we considered the calcification of the pallidum in this subject to be merely coincidential. In all other cases the CT scan findings were similar to those referred to in the literature. ${ }^{38} 39$

The 21 patients make up $9 \cdot 2 \%$ of the 228 cases of
Parkinsonism seen at our clinic. In the majority of cases the illness started with tremor and continued its course in a mixed form. Unlike other series ${ }^{632}$ tremor remained an important symptom. In spite of the long course of the disease (19 years on average) only four cases were found to be in an advanced form of disability. Our patient who died was in Hoehn and Yahr stage III. The length of the illness and the good and sustained response to levodopa are in keeping with previous reports. ${ }^{5-7}$ The incidence of side effects to levodopa has been low (average duration of treatment-5.4 years). In the four patients in an advanced stage intolerance to levodopa was due to severe peak dose dyskinesias. "On-off" and "wearingoff" phenomenon were also observed in these cases. This type of response to levodopa has also been observed by others. ${ }^{67}$

Our series shows significant differences from those hitherto described in terms of familial incidence of Parkinsonism ${ }^{1-367}$ as well as metabolic disorders found in the patients and their relatives. ${ }^{7} \mathrm{We}$ found Parkinsonism in only two siblings, both of whom demonstrated a similar clinical onset and course. Familial tremor was found in only three cases, all in group 1. Thyroidopathy, diabetes mellitus, or macrocytic anaemia was not found in any of the cases. Arterial hypertension was detected in only four cases. Five patients admitted to having a family history of hypertension and three of diabetes mellitus. There was no thyroid disease in the relatives.

We conclude, from our series, that there is no evidence suggesting that subjects beginning apparent idiopathic Parkinson's disease before the age of 40 have any disorder other than idiopathic Parkinson's disease.

We thank Professor Melvin Yahr for reviewing the manuscript. We also thank Dr J Rocha Melo for his neuroradiological investigations of the patients and Mrs Teresa Vasconcelos for her editorial assistance.

\section{References}

1 Willige H. Uber paralysis agitans in jugendlichem. Alter Z Gesamte Neurol Psychiatr 1911;4:520.

2 Mjones H. Paralysis agitans: A clinical and genetic study. Acta Psychiatr Scand (Suppl) 1949;54:1-195.

3 Ota Y, Miyoshi S, Ueda O, et al. Familial paralysis agitans juvenilis. A clinical, anatomical and genetic study. Folia Psychiatr Neurol Jap 1958;12:112-21.

4 Martin WE, Resch JA, Baker AB. Juvenile Parkinsonism. Arch Neurol 1971;25:494-500.

5 Carlier G, Dubru JM. Familial juvenile Parkinsonism. Acta Paediatr Belg 1979;32:123-7.

6 Yokochi M, Narabayashi H. Clinical characteristics of Juvenile Parkinsonism. In: Rose FC, Capildeo R, eds. Research Progress in Parkinson's Disease. London: Pitman Medical, 1981:35-9. 
7 Barbeau A, Pourcher E. New data on the genetics of Parkinson's disease. Can J Neurol Sci 1982;9:53-66.

8 Barbeau A, Roy M, Boyer L. Genetic studies in Parkinson's Disease. In: Hassler RG, Christ JF, eds. Advances in Neurology. Vol. 40. New York: Raven Press, 1984:333-9.

9 Barbeau A, Roy M. Familial subsets in idiopathic Parkinson's disease. Can J Neurol Sci 1984;11:144-50.

10 Eadie MJ. Olivo-ponto-cerebellar atrophy (chap.20, 21, 22). In: Vinkin PJ, Bruyn GW, eds. Handbook of Clinical Neurology. Vol. 21. Amsterdam: NorthHolland, 1975:415-57.

11 Berciano J. Olivo-ponto-cerebellar-atrophy. A review of 117 cases. J Neurol Sci 1982;53:253-72.

12 Adams RD. The striatonigral degenerations. In: Vinken PJ, Bruyn GW, eds. Handbook of Clinical Neurology. Vol. 6. Amsterdam: North-Holland, 1968:694-702.

13 Shy GM, Drager GA. A neurological syndrome associated with orthostatic hypotension. Arch Neurol 1960;2:511-27.

14 Steele JC. Progressive supranuclear palsy. Brain 1972;95: 693-704.

15 Coutinho P, Andrade C. Autosomal dominant system degeneration in Portuguese families of the Azores Islands. Neurology 1978;28:703-9.

16 Hirano A, Kurland LT, Krooth RS, Lessell S. Parkinsonism-dementia complex, an endemic disease on the island of Guam: clinical features. Brain 1961;84:642-61.

17 Hirano A, Malamund N, Kurland LT. Parkinsonismdementia complex, an endemic disease on the island of Guam: pathological features. Brain 1961;84:662-79.

18 Herishanu Y, Noah Z. On acute Encephalitic Parkinsonian Syndrome. Eur Neurol 1973;10:117-24.

19 Duvoisin R, Yahr M. Encephalitis and Parkinsonism. Arch Neurol 1965;12:227-39.

20 Rail D, Scholtz C, Swash M. Post-encephalitic Parkinsonism: current experience. J Neurol Neurosurg Psychiatry 1981;44:670-6.

21 Hoehn M, Yahr M. Parkinsonism: onset, progression and mortality. Neurology 1967;17:427-42.

22 Uzman LL, Jakus MA. The Kayser-Fleicher ring: a histochemical and electron microscopy study. Neurology 1957;7:341-55.

23 Scheinberg IH, Gitlin D. Deficiency of ceruloplasmin in patients with hepatolenticular degeneration (Wilson's disease). Science 1952;116:484-5.

24 Wilson SAK. Progressive lenticular degeneration: a familial nervous disease associated with cirrhosis of the liver. Brain 1912;34:295-304.

25 Bittenbender JB, Quedfasel FA. Rigid and akinetic form of Huntington's chorea. Arch Neurol 1962;7:275-88.

26 Bird MT, Paulson GW. Early onset rigid Huntington's chorea. Neurology 1970;20:400.

27 Izumi K, Inove N, Shirabe T, et al. Failed levodopa therapy in striatonigral degeneration. Lancet $1971 ; \mathbf{i}: 1355$.

28 Rajput A, Kazi KA, Rozdilsky B. Striatonigral degeneration: Response to levodopa therapy. J Neurol Sci 1972; 16:331-41.

29 Hunt JR. Progressive atrophy of the globus pallidus (primary atrophy of the pallidal system). Brain 1917;40:58-148.

30 Van Bogaert L. Contribution clinique et anatomique à l'étude de la paralysie agitante juvénile primitive (atrophie progressive du globe pâle de Ramsay-Hunt). Rev Neurol (Paris) 1930;2:315-26.

31 Davison C. Pallido-pyramidal disease. J Neuropathol Exp Neurol 1954;13:50-9.

32 Yokochi M, Narabayashi $H$, lizuka R, Nagatsu T. Juvenile Parkinsonism-Some clinical, Pharmacological and Neuropathological aspects. In: Hassler RG, Christ JF, eds. Advances in Neurology. Vol. 40. New York: Raven Press, 1984:407-13.

33 Koller W, Cochran J, Klawans H. Calcification of the basal ganglia Computerized tomography and clinical correlation. Neurology 1979;29:328-39.

34 Brannan TS, Burger AA, Chaudary MY. Bilateral basal $\square \omega$ ganglia calcification visualized on $C T$ scan. $J$ Neurolo Neurosurg Psychiatry 1980;43:403-6.

35 Klawans H, Lupton M, Simon L. Calcification of the basal ganglia as a cause of levodopa-resistant Parkinsonism. Neurology 1976;26:221-5.

36 Muenter MD, Whisnant JP. Basal ganglia calcification, hypoparathyroidism and extrapyramidal motor manifestations. Neurology 1968;18:1075-83.

37 Sachs C, Sjöberg HE, Ericson K. Basal ganglia calcifications on CT: Relation to hypoparathyroidism. Neurology 1982;32:779-82.

38 Sroka H, Elizam TS, Yahr M, Burger A, Mendoza MR. Organic mental syndrome and confusional states in Parkinson's disease: Relation to computerized tomographic signs of cerebral atrophy. Arch Neuro 1981;38:339-42.

39 Portin R, Raininko R, Rinne UK. Neuropsychological disturbances and cerebral atrophy determined by computerized tomography in Parkinsonian patients with long-term levodopa treatment. In: Hassler RG, Christ JF, eds. Advances in Neurology. Vol. 40. New York: Raven Press, 1984:333-9. 